\title{
Cytotoxic T cells in AIDS colonic cryptosporidiosis
}

D Reijasse, N Patey-Mariaud de Serre, D Canioni, M Huerre, E Haddad, M Leborgne, $S$ Blanche, $\mathrm{N}$ Brousse

\begin{abstract}
BackgroundlAims-It is not known how enteric cryptosporidiosis induces severe intestinal impairment despite minimal invasion by the parasite. The aim of this study was to analyse the histological features and locally implicated immune cells in colonic biopsies of AIDS related cryptosporidiosis.

Patients/Methods-Colonic biopsies from patients with AIDS related cryptosporidiosis (n = 10, group I), patients with AIDS but without intestinal infection $(n=9$, group II), and human seronegative controls ( $\mathrm{n}=9$, group III) were studied. Using immunohistochemistry the infiltrating mononuclear cells were analysed in both the epithelium and lamina propria for the expression of CD3, CD8, TiA1, granzyme $B$, and CD68 and for glandular expression of human major histocompatibility complex DR antigen (HLA-DR).

Results-Severe histological changes, resulting in abundant crypt epithelial apoptosis and inflammatory infiltrate in the lamina propria, were seen in all biopsies from group $I$. A significant increase of $\mathrm{CD8}+, \mathrm{TiA1}+$, and granzyme $\mathrm{B}+\mathrm{T}$ cells in the lamina propria and HLA-DR glandular expression was noted in group I compared with groups II and III. However, the number of intraepithelial lymphocytes, lamina propria CD3 $+\mathrm{T}$ cells, and macrophages was not significantly increased in cryptosporidiosis specimens compared with controls.

Conclusion-Epithelial apoptosis mediated by granzyme $\mathrm{B}+$ cytotoxic host $\mathrm{T}$ cells might play a major role in the development of colonic lesions in AIDS related cryptosporidiosis.

(F Clin Pathol 2001;54:298-303)
\end{abstract}

Keywords: cryptosporidiosis; acquired immunodeficiency syndrome; colon; apoptosis; cytotoxicity; immunochemistry

Department of Pathology, Institut Pasteur, 75724 Paris, Cedex 15, France M Huerre

Correspondence to: Dr Brousse, Service d'Anatomie Pathologique, Hôpital Necker-Enfants Malades, 149, Rue de Sèvres, 75743 Paris Cedex 15,

France

nicole.brousse@

nck.ap-hop-paris.fr

Accepted for publication 17 August 2000

Enteric cryptosporidiosis is a common cause of diarrhoea, especially in immunocompromised patients. ${ }^{1}$ However, the pathophysiology of the disease is not clear. Three mechanisms have been proposed, ${ }^{2}$ namely: parasite induced damage of intestinal architecture by direct cytotoxicity, the production of an enterotoxic moiety by the parasite, and the release of inflammatory metabolites as part of the host response to the infection.

Histological analysis of intestinal cryptosporidiosis frequently reveals a non-specific inflammatory infiltrate associated with glandular alterations. ${ }^{3-12}$ It preferentially affects the small bowel, inducing watery diarrhoea and malabsorption, with or without villous atrophy. ${ }^{5}$ Most studies have concerned the small bowel and only a few reports have mentioned colonic biopsies. ${ }^{6-9}$ Thus, colonic features are less well described and seem less severe than those observed in the small bowel.

To our knowledge, there is no previous immunopathological study that has evaluated the immune cells implicated locally in patients with AIDS; the few studies performed have been in murine models of cryptosporidiosis infection ${ }^{13}{ }^{14}$ or in vitro. ${ }^{15}$

The aim of our study was to analyse the histological changes seen in colonic biopsies from 10 patients with AIDS infected with cryptosporidium and to identify, by means of immunohistochemistry, the immune cells that are implicated locally. We focused on the frequent occurrence of epithelial apoptosis in colonic cryptosporidiosis, which seems to be induced by CD8+ cytotoxic $\mathrm{T}$ cells expressing granzyme $\mathrm{B}$. This cytotoxic process mediated by the host immune response could play a major role in the development of the intestinal impairment seen in cryptosporidiosis.

\section{Materials and methods}

PATIENTS

Group I

We studied retrospectively 10 colonic biopsies from 10 patients with AIDS and histologically confirmed intestinal cryptosporidiosis (one female and nine male patients; mean age, 27.4 years; SE, 11.5; mean CD4 count, $90 / \mathrm{mm}^{3}$; SE, 141). Table 1 summarises the main clinical and biological characteristics of the patients. Cryptosporidiosis was the only opportunistic infection of the gastrointestinal tract in all patients (except oral or oesophageal candidiosis). For one patient (patient 3), cryptosporidiosis was also identified on ileal biopsies. For the nine other patients, intestinal biopsies were not available.

Cytomegalovirus colonic infection was excluded by both a normal colonoscopy and the
Control groups

Group II: nine intestinal biopsies (seven colon, two rectal) from patients with AIDS but without opportunistic infection of the intestinal tract were selected. They were performed in 
Table 1 Colonic cryptosporidiosis: clinical and biological findings

\begin{tabular}{|c|c|c|c|c|c|c|c|c|c|c|c|}
\hline & & \multicolumn{10}{|c|}{ Cryptosporidiosis (group I) } \\
\hline & & 1 & 2 & 3 & 4 & 5 & 6 & 7 & 8 & 9 & 10 \\
\hline Age years & & 12 & 16 & 34 & 8 & 32 & 30 & 33 & 30 & 41 & 38 \\
\hline $\mathrm{CD} 4\left(/ \mathrm{mm}^{3}\right)$ & & 365 & 0 & 69 & 345 & 15 & 36 & 5 & 7 & 50 & 8 \\
\hline \multirow[t]{2}{*}{$\begin{array}{l}\text { Anti-retroviral } \\
\text { therapy }\end{array}$} & Anterior & $\begin{array}{l}\mathrm{AZT} \\
\mathrm{DDI}\end{array}$ & AZT & DDC & $\mathrm{O}$ & $\mathrm{AZT}$ & $\begin{array}{l}\text { AZT } \\
\text { DDI }\end{array}$ & AZT & $\mathrm{AZT}$ & $\mathrm{AZT}$ & $\mathrm{AZT}$ \\
\hline & Actual & DDC & $\mathrm{O}$ & $\begin{array}{l}\text { AZT } \\
\text { 3TC } \\
\text { IN }\end{array}$ & DDI & $\mathrm{AZT}$ & $\mathrm{AZT}$ & $\begin{array}{l}\text { AZT } \\
\text { 3TC }\end{array}$ & $\begin{array}{l}\text { AZT } \\
\text { DDI }\end{array}$ & $\begin{array}{l}\text { AZT } \\
\text { DDI }\end{array}$ & $\mathrm{O}$ \\
\hline Endoscopy & & $\mathrm{N}$ & $\mathrm{N}$ & $\begin{array}{l}\text { UI } \\
\text { EC }\end{array}$ & EC & $\mathrm{N}$ & $\mathrm{N}$ & $\mathrm{UC}$ & $\mathrm{N}$ & UC & $\mathrm{UC}$ \\
\hline
\end{tabular}

Age and CD4 count: at the date of colonoscopy (initial).

AZT, azidothymidine; DDI, dideoxyinosine; DDC, dideoxycytidine; 3TC, 3-thiacytidin; IN, indinavir; N, normal; UI, ulcerative ileitis; EC, erythematous colitis; UC, ulcerative colitis.

nine patients with similar CD4 counts (mean, $107 / \mathrm{mm}^{3}$; SE, 130) and similar treatment (azidothymidine, dideoxycytidine, dideoxyinosine, 3-thiacytidin) to the cryptosporidiosis group. The mean (SE) age was 46 (9) years and one patient was female and eight patients were male. Colonoscopies were performed for diarrhoea with or without abdominal pain.

Group III: nine intestinal biopsies (six colon, three rectum) considered as normal were selected. They were performed in nine patients (six male and three female) similar in age (mean, 26 years; SE, 19.8) to the cryptosporidiosis group. Colonoscopies were performed for abdominal pain (four patients), rectorrhagia (three patients), and weight loss (two patients).

\section{METHODS}

\section{Histopathological analysis}

The biopsy specimens were fixed in formalin or Bouin's fluid, embedded in paraffin wax and oriented for histological sectioning. Sections were stained with haematoxylin and eosin, periodic acid Schiff, and Giemsa to exclude the presence of other pathogens. Specimens were assessed by a physician (DR) who was unaware of the clinical features of the patients and the stool results. The following histological features were assessed: (1) glandular abnormalities (defined as degenerative epithelial changes or atrophy), glandular dilatation or disappearance, crypt abscesses, and glandular epithelial apoptotic bodies defined as round to oval membrane bound fragments of basophilic pyknotic material expressed as cells in apoptosis/10 glands $^{18}{ }^{19}$; and (2) the presence of inflammatory cells in the lamina propria, scored by the immunopathological analysis.

Immunopathological analysis

Primary monoclonal antibodies were labelled with a three stage indirect immunoperoxidase technique. Tissue sections were cut at $5 \mu \mathrm{m}$ on superfrost slides from the paraffin wax embedded blocks and immunostained with monoclonal antibodies (table 2). Immunostaining results were expressed quantitatively. CD3, CD8, and TiA1 positive cells were counted in the surface epithelium (for each 100 epithelial cells). In the lamina propria, CD3, CD8, TiA1, granzyme $\mathrm{B}$, and $\mathrm{CD} 68$ positive cells were expressed as the mean percentage of mononuclear cells counted on six representative grids at $\times 1000$ magnification. In the cryptosporidiosis group, two grids were counted on areas with increased cellularity associated with epithelial lesions, two others were over areas with increased cellularity without epithelial lesions, and two were over areas considered to be normal or subnormal. In the control group, six grids were counted at random because the histological features were homogeneous with no lesions. Glandular expression of HLA-DR (human major histocompatibility complex DR antigen) (for each 10 glands), reflecting immune stimulation, was measured in the entire biopsy. Epithelial cell proliferation was studied by assessing Ki-67 expression. Specimens were assessed by a physician (DR) unaware of the clinical features of the patients and the stool results; each grid was counted twice, and the mean of the two counts was recorded. Eight specimens from three patients with cryptosporidiosis, three human immunodeficiency virus (HIV) negative controls, and two patients with AIDS but without intestinal infection were also assessed by a pathologist (NPMdS), unaware of the clinical features of the patients, the stool results, and the results of the first count. We found an interobserver correlation of $85 \%$.

Intensity of infection

Because a significant correlation between the numbers of cryptosporidium organisms seen

Table 2 Monoclonal antibody panel

\begin{tabular}{llll}
\hline $\begin{array}{l}\text { Antibody/ } \\
\text { Antigen }\end{array}$ & Dilution & Cell or antigen identified & Source \\
\hline CD3 & $1 / 100$ & T cells & Dako (Glostrup, Denmark) \\
CD8 & $1 / 100$ & Cytotoxic T cells & Dako \\
TiA1 & $1 / 200$ & Cytotoxic granules of CD4+, CD8+ T cells, and NK cells & Coulter (Cambridge, UK) \\
Granzyme B & $1 / 50$ & Granzyme B & Sanbio (Uden, Netherlands) \\
CD68 & $1 / 300$ & Macrophages & Dako \\
HLA-DR & $1 / 100$ & HLA-DR & Dako \\
Ki-67 & $1 / 400$ & Proliferative cells & Immunotech (Marseille, \\
& & & France)
\end{tabular}

HLA-DR, human major histocmpatibility complex DR antigen; NK, natural killer. 
Table 3 Histologicalal results of colonic biopsies in cryptosporidiosis

\begin{tabular}{llll}
\hline & $\begin{array}{l}\text { Cryptosporidiosis (group } \\
I) n=10\end{array}$ & Group II & Group III \\
\hline Apoptosis (/10 glands) & $4.4(4.6)^{\star}$ & $0.3(0.8)$ & $0.02(0.06)$ \\
Intraluminal glandular cellular necrosis & $100 \%$ & 0 & 0 \\
Glandular abnormalities & $100 \%$ & 0 & 0 \\
Glandular dilatation & $90 \%$ & 0 & 0 \\
Glandular disappearance & $70 \%$ & 0 & 0 \\
Crypt abscess & $10 \%$ & 0 & 0 \\
Eosinophil increase & $60 \%$ & 0 & 0 \\
Surface covered by cryptosporidium (\%) & $13.9(16.5)(1-50 \%)$ & 0 & 0 \\
\hline
\end{tabular}

Values for apoptosis and surface covered by cryptosporidium are means (SE) of samples within each group.

Cryptosporidiosis $v$ HIV negative controls: ${ }^{\star}, \mathrm{p}<0.05$.

Cryptosporidiosis $v$ AIDS without intestinal infection: $\S, \mathrm{p}<0.05$.

on small bowel biopsy and morphological abnormalities $^{34}$ has been observed, the intensity of infection was scored and expressed as an estimate of the proportion of the surface epithelium occupied by cryptosporidium.

Statistical analysis

Results are reported as means (SE). Significance was calculated using the Student's $t$ test.

\section{Results}

HISTOPATHOLOGY

The results are summarised in table 3 . In all patients of group I infected with cryptosporidium, we found severe colonic lesions, characterised by focal glandular destruction or disappearance, associated with some glandular dilatations and epithelial apoptosis. Pluricellular apoptosis (fig 1A) was seen in nine specimens, with a mean (SE) intensity of 4.4 (4.6) cells in apoptosis/10 glands in cryptosporidiosis. In contrast, epithelial apoptosis was seen in three of nine specimens from group
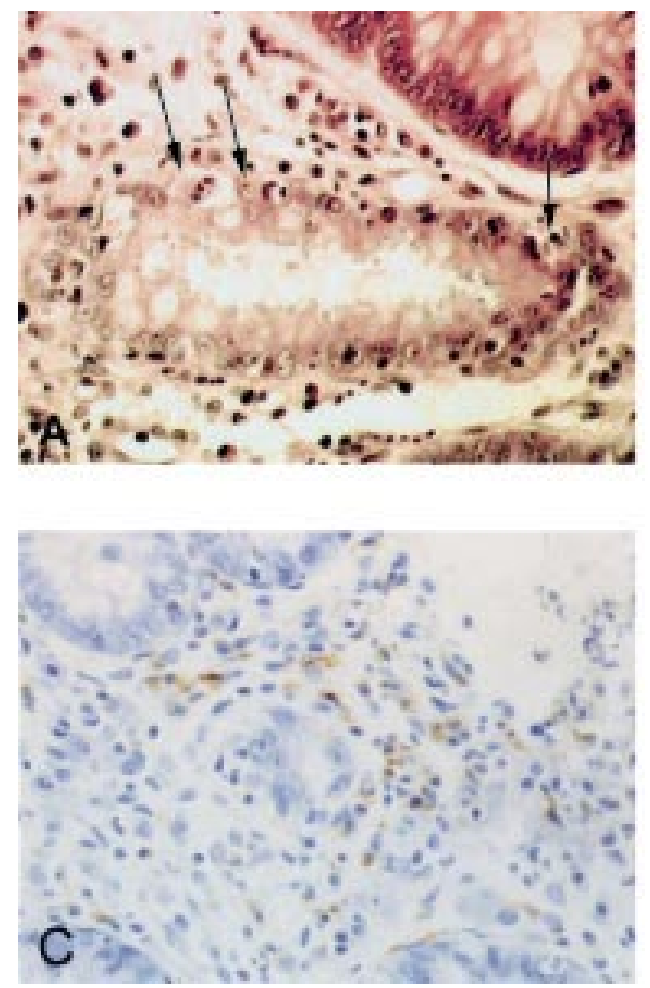

Figure 1 Histological and immunopathological results of colonic biopsies in patients with AIDS and cryptosporidiosis: (A) pluricellular apoptosis (arrows) is seen in a gland infected with cryptosporidiosis. Lamina propria cellularity is increased, especially around altered glands; infiltrating cells include macrophages, plasma cells, and lymphocytes expressing (B) CD3, (C) TiA1, and (D) granzyme $B$.

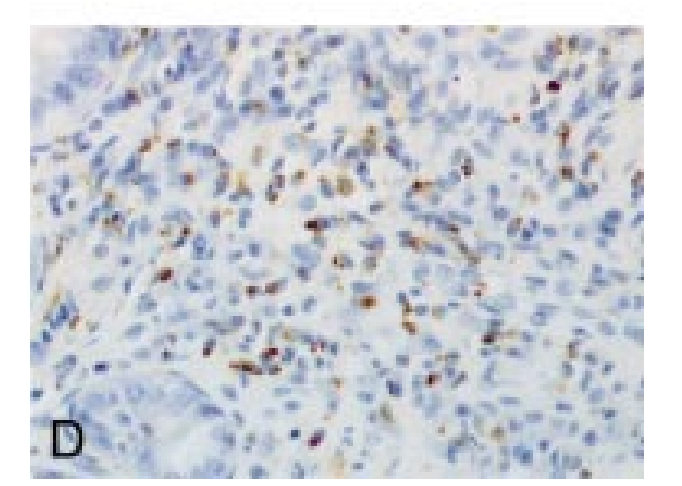

II patients, with a mean (SE) intensity of 0.3 $(0.8) / 10$ glands $(p<0.05)$ and in one of nine specimens from the HIV negative controls (group III), with a mean (SE) intensity of 0.02 $(0.06) / 10$ glands $(p<0.05)$. The cellularity of the lamina propria was increased in all group I patients, with a diffuse pattern and predominantly around altered glands. In six biopsies, the mononuclear cell infiltrate was associated with a pronounced increase in eosinophils. The increased.

Apoptotic bodies of epithelial cells were seen mainly in the glandular compartment and not in the surface epithelium.

\section{IMMUNOPATHOLOGY}

Results are summarised in table 4 and fig $1 \mathrm{~B}-\mathrm{D}$. We found a significant increase in lamina propria cellularity, mainly around altered glands, in the cryptosporidiosis group I compared with control groups II and III. This increase involved $\mathrm{T}$ CD3+ lymphocytes, mostly $\mathrm{CD} 8+$, TiA1+, and granzyme $\mathrm{B}+$. We also noted a significant increase of HLA-DR expression in the surface and glandular epithelium in cryptosporidiosis. However, we saw no significant differences between controls and the cryptosporidiosis group in terms of IEL number and phenotype. Although the lamina propria macrophage (CD68+) count was increased in cryptosporidiosis group I, compared with groups II and III, the difference was not significant. Macrophages were preferentially located in the upper part of the lamina propria, as in normal colonic mucosa, and around altered glands. In group II (patients

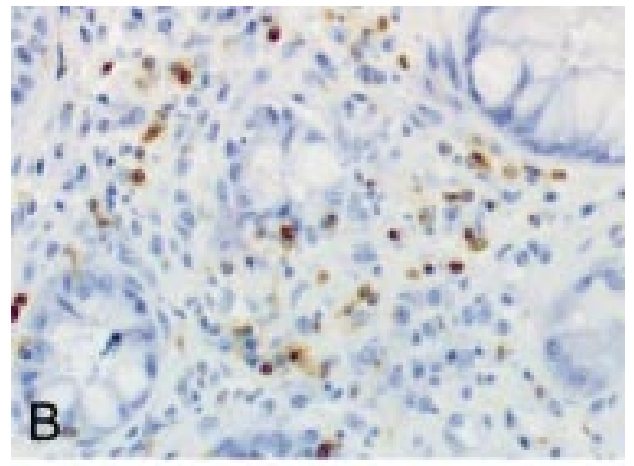
3, intraepithelial lymphocytes (IELs) were not 
Table 4 Immunopathological results of colonic biopsies in cryptosporidiosis and controls

\begin{tabular}{|c|c|c|c|}
\hline & $\begin{array}{l}\text { Cryptosporidiosis (group } \\
\text { I) }\end{array}$ & $\begin{array}{l}\text { AIDS without intestinal } \\
\text { infection (group II) }\end{array}$ & Control (group III) \\
\hline Number of biopsies & 10 & 9 & 9 \\
\hline \multicolumn{4}{|l|}{ IELs } \\
\hline CD3 & $6.1(2.9)$ & $10.7(3.8)$ & $8.2(5.1)$ \\
\hline CD8 & $3.5(1.8)$ & $5.5(4.3)$ & $5.3(3.2)$ \\
\hline TiA1 & $6.9(4.6)$ & $9.7(2.9)$ & $6.6(3.6)$ \\
\hline \multicolumn{4}{|l|}{ Lamina propria } \\
\hline $\mathrm{CD} 3$ & $23.8(4.8)$ & $20.4(7.9)$ & $15.2(1.3)^{\star}$ \\
\hline CD8 & $22.1(2.8) \rrbracket$ & $15.2(6.7) \#$ & $7.9(1.4)^{\star \star}$ \\
\hline TiA1 & $23.8(5.1) \oint 8$ & 16.9 (4.7)\#\# & $7.7(2.8)^{\star \star}$ \\
\hline Granzyme B & $8.7(2.6) \Phi 95$ & $2.2(2.4) \#$ & $0.2(0.4)^{\star \star}$ \\
\hline CD68 & $34.9(4.8)$ & $32.8(6.7)$ & $30.6(6.6)$ \\
\hline Glandular expression of HLA-DR (/10 glands) & $6.8(2.3) \S$ & $2.4(4.3)$ & 0 \\
\hline
\end{tabular}

Phenotypic analysis of infiltrating lymphoid cells within the lamina propria and surface epithelium. Values are expressed as percentage of cells of phenotype shown as a subset of all nucleated cells within six representative grids (lamina propria) or cells of phenotype/100 epithelial cells (surface epithelium).

Values are means (SE) of samples.

Cryptosporidiosis $v$ HIV negative controls: ${ }^{\star}, \mathrm{p}<0.001$; ${ }^{\star \star}, \mathrm{p}<0.00001$.

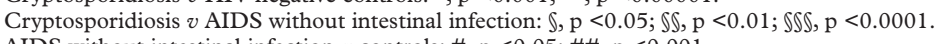

AIDS without intestinal infection $v$ controls: \#, $\mathrm{p}<0.05$; \#\#, $\mathrm{p}<0.001$.

HLA-DR, human major histocompatibility complex DR antigen; IELs: intraepithelial lymphocytes.

with AIDS but without intestinal infection), compared with group III HIV negative controls, there was a significant increase of CD8+, $\mathrm{TiA} 1+$ cytotoxic $\mathrm{T}$ cells expressing granzyme $\mathrm{B}$ and a non-significant increase of CD $3+\mathrm{T}$ cells in the lamina propria. We found no significant differences between groups II and III in terms of IEL number and phenotype. The histopathological results showed that the IELs were not increased in all the groups studied. The phenotype of the IELs was normal (table 4) and the expression of granzyme B was restricted to rare IELs in the three groups. $\mathrm{Ki}-67$ expression was limited to glandular epithelial cells in the three groups, and was absent in the deeper glandular neuroendocrine epithelial cells. The surface epithelial cells did not express Ki-67.

CORRELATION WITH INTENSITY OF INFECTION The clinical presentation of all patients in group I was similar-diarrhoea and abdominal pain.

In seven patients, less than $10 \%$ of the surface area of the epithelium was covered by cryptosporidium. In the other three patients more than $30 \%$ of the epithelial surface area was covered by cryptosporidium.

No correlation was found between the intensity of infection by cryptosporidium (estimated by epithelium surface area covered) and the histopathological or immunopathological data.

\section{Discussion}

Our study emphasises the fact that colonic cryptosporidiosis occurring in AIDS can induce severe histological lesions. The most interesting point, to our knowledge not described previously in humans, is the finding of multiple glandular epithelial cells in apoptosis associated with an inflammatory infiltrate with a distinct phenotype of CD8+, TiA1+, and granzyme $\mathrm{B}+\mathrm{T}$ cells. Most previous studies have concerned the small bowel, which is affected preferentially, especially the ileal mucosa where most organisms and the most severe epithelial changes are seen. ${ }^{6}$ These lesions are reported as a non-specific inflammatory infiltrate in the lamina propria and can include plasma cells, lymphocytes, and macrophages. ${ }^{3-12}$ In our study, macrophages and plasma cells were present but not significantly increased. The significant expression of HLA-DR on glandular epithelial cells suggests an immune reaction of glandular epithelial cells. IELs, which are thought to be important in the mucosal immune response of cryptosporisiosis infected mice, were not increased in our study. ${ }^{13}$ Lamina propria $\mathrm{T}$ cells appear to be implicated in the cytotoxic mechanism.

Colonic histological features described as non-specific colitis have been reported to be less frequent and severe than those seen in the small bowel..$^{5-8}$ However, our patients all had more severe colonic lesions than is usually described. This discrepancy could be explained by the fact that our patients all had severe clinical manifestations, with intractable watery cryptosporidium induced diarrhoea.

We found no correlation between the intensity of infection and histopathological or immunopathological data, contrary to other studies. ${ }^{19} 20$ This discrepancy could be related to the fact that we did not study the entire intestinal tract. The clinical features and course may depend on the localisation of the parasite. Severe small bowel dysfunction occurs in patients with small bowel cryptosporidiosis involving mainly small bowel crypts. ${ }^{9}$

Cryptosporidiosis commonly induces profuse watery diarrhoea and severe histological impairment. ${ }^{1}$ Ultrastructurally, the organisms can be seen invaginating the apical membranes of epithelial cells, forming interposing membrane layers known as feeder organelles. ${ }^{21}$ It is difficult to explain how such minimal invasion can produce profound diarrhoea and severe histological changes. The most singular observation in our series is the presence of a severe pluricellular apoptosis readily identified by conventional light microscopy ${ }^{19}$ not balanced by $\mathrm{Ki}-67$ epithelial proliferation. An in vitro model of biliary cryptosporidiosis demonstrated the direct cytopathic effect of the organism via an apoptotic mechanism. ${ }^{22}$ These very unusual apoptotic lesions, rarely seen under normal conditions, ${ }^{23}$ have been described previously at the colonic level ${ }^{2425}$ in 
constitutional immunodeficiency ${ }^{26}$ and also in graft versus host disease, ${ }^{27}$ inflammatory bowel disease, ${ }^{28}$ drug related lesions, ${ }^{18}$ melanosis coli, ${ }^{29}$ radiation colitis, ${ }^{29}$ and infectious colitis. ${ }^{30}$ Similar apoptotic lesions have also been described previously in AIDS, sometimes in association with intestinal opportunistic infections, ${ }^{24} 25$ including cryptosporidiosis ${ }^{31}$ essentially in cases of acute HIV infectioninducing cell apoptosis by an unknown mechanism. ${ }^{32}$

To specify how this apoptotic process occurs and which immune cells are implicated locally, we conducted an immunohistochemical study. We found a significant increase of CD3 $+\mathrm{T}$ cells in the lamina propria, with a pronounced predominance of cytotoxic cells (CD8+, TiA1+) expressing granzyme B. Our findings agree with previous immunohistochemical studies $^{33-35}$ that showed two to three fold increases in CD8+ cells in the intestine of patients with AIDS. Cytotoxic CD8+ cells, the functions of which are moderately or not impaired in AIDS and which predominate in the lamina propria of patients with AIDS, could be activated and mediate a cytotoxic response, leading to epithelial damage by apoptosis induced by granzyme. Along with Fas/Fas ligand, the granzyme/perforin system is the preferential pathway used by cytotoxic CD8+ $\mathrm{T}$ cells to induce apoptosis ${ }^{36}$ and caspases are thought to be involved in this process. $^{37} 38$

The presence of a CD8+ cytotoxic $\mathrm{T}$ cell infiltrate expressing granzyme B in the lamina propria of patients with cryptosporidiosis suggests that cryptosporidium induced lesions are caused primarily by the host immune response.

Most recent studies have focused on the importance of cellular immunity in the response to cryptosporidium. ${ }^{39-42}$ However, in AIDS, it has been showed that peripheral blood mononuclear cells do not proliferate in response to cryptosporidium antigens. ${ }^{32}$ In addition, mucosal cytokine mediated inflammatory responses do not play an important role in cryptosporidia diarrhoea. ${ }^{43}$ Together with cellular immunity, the humoral response to cryptosporidium infection might help protect against the organism. ${ }^{44-46}$ However, despite locally produced IgA in patients with AIDS, pathogen specific mucosal antibody responses fail to clear the parasite. ${ }^{474}$

The secretion of an enterotoxin by cryptosporidium could contribute to the apoptotic lesions. ${ }^{49}$ However, despite experimental data suggesting the existence of a toxin, no such toxin has been identified definitively. ${ }^{5051} \mathrm{~A}$ direct cytopathogenic effect of the parasite could also contribute to the histological lesions in the intestinal epithelium; this has been demonstrated in cultured human biliary epithelium, ${ }^{22}$ with the organisms having a direct effect on intestinal cell permeability in culture..$^{52}$ Our study found no correlation between the intensity and the localisation of infection and histopathological or immunopathological results. Thus, these results are not in favour of a direct role for cryptosporidium in apoptosis induction.
In conclusion, intestinal cryptosporidiosis in AIDS induces severe histological lesions, with pluricellular apoptosis and a significant increase in CD8+ cytotoxic lymphocytes expressing granzyme $\mathrm{B}$ in the lamina propria. Together, the minimal invasion, the relatively low intensity of infection by cryptosporidium, and the absence of a correlation between the severity of the lesions and the intensity of infection suggest that the immune cytotoxic granzyme B response of the host could play a major role in the development of the colonic histopathological impairment seen in cryptosporidiosis.

The authors thank M Lanniel for expert technical assistance, J-P Monnet for preparing the photomicrographs, and M Grimal for helpful secretarial assistance.

1 Heyworth MF. Parasitic diseases in immunocompromised hosts. Cryptosporidiosis, isosporiasis and strongyloidiasis. Gastroenterol Clin North Am 1996;25:691-707.

2 Steiner TS, Guerrant RL. The pathogenesis of and host response to Cryptosporidium parvum. Curr Opin Infect Dis 1996;9:156-60

3 Goodgame RW, Genta RM, White AC, et al. Intensity of infection in AIDS-associated cryptosporidiosis. F Infect Dis 1993;167:704-9.

4 Goodgame RW, Kimball K, Ou C, et al. Intestinal function and injury in acquired immunodeficiency syndromerelated cryptosporidiosis. Gastroenterology 1995;108:107582.

5 Kelly P, Makumbi FA, Carnaby S, et al. Variable distribution of Cryptosporidium parvum in the intestine of AIDS patients revealed by polymerase chain reaction. Eur 7 Gastroenterol Hepatol 1998;10:855-8.

6 Godwin TA. Cryptosporidiosis in the acquired immunodeficiency syndrome: a study of 15 autopsy cases. Hum Pathol 1991;22:1215-24.

7 Modigliani R, Bories C, Le Charpentier Y, et al. Diarrhoea and malabsorption in acquired immune deficiency syndrome: a study of four cases with special emphasis on syndrome: a study of four cases with special emphasis on

8 Dworkin B, Wormser GP, Rosenthal WS, et al. Gastrointestinal manifestations of the acquired immunodeficiency syndrome: a review of 22 cases. Am $\mathcal{F}$ Gastroenterol 985;80:774-8

9 Clayton F, Heller T, Kotler DP. Variation in the enteric distribution of cryptosporidia in acquired immunodeficiency syndrome. Am $\mathcal{F}$ Clin Pathol 1994;102:420-5.

10 Kotler DP, Francisco A, Clayton F, et al. Small intestinal injury and parasitic diseases in AIDS. Ann Intern Med 1990;113:444-9.

11 Gillin JS, Shike M, Alcock N, et al. Malabsorption and mucosal abnormalities of the small intestine in the acquired immunodeficiency syndrome. Ann Intern Med 1985;102: 619-22.

12 Isaacs D, Hunt GH, Phillips AD, et al. Cryptosporidiosis in immunocompetent children. $\mathcal{F}$ Clin Pathol 1985;38:76-81.

13 Chai JY, Guk SM, Han HK, et al. Role of intraepithelial lymphocytes in mucosal immune responses of mice experimentally infected with Cryptosporidium parvum. I Parasitol 1999;85:234-9.

14 Culshaw RJ, Bancroft GJ, McDonald V. Gut intraepithelial lymphocytes induce immunity against Cryptosporidium infection through a mechanism involving gamma interferon production. Infect Immun 1997;65:3074-9.

15 Wyatt CR, Brackett EJ, Barrett WJ. Accumulation of mucosal T lymphocytes around epithelial cells after in vitro infection with Cryptosporidium parvum. F Parasitol 1999; 85:765-8.

16 Beaugerie L, Cywiner-Golenzer C, Monfort L, et al. Definition and diagnosis of cytomegalovirus colitis in patients infected by human immunodeficiency virus. If Acquir infected by human immunodeficienc Defic Syndr 1997;14:423-9.

17 Goodgame RW. Gastrointestinal cytomegalovirus disease. Ann Intern Med 1993;119:924-35.

18 Lee FD. Importance of apoptosis in the histopathology of drug related lesions in the large intestine. $\mathcal{F}$ Clin Pathol 1993;46:118-22.

19 Grasl-Kraupp B, Ruttkay-Nedecky B, Koudelka H, et al. In situ detection of fragmented DNA (TUNEL assay) fails to discriminate among apoptosis, necrosis, and autolytic cell death: a cautionary note. Hepatology 1995;21:1465-8.

20 Rivasi F, Rossi P, Righi E, et al. Gastric cryptosporidiosis: correlation between intensity of infection and histological alterations. Histopathology 1999;34:405-9.

21 Marcial MA, Madara JL. Cryptosporidium: cellular localization, structural analysis of absorptive cell-parasite membrane-membrane interactions in guinea-pigs, and suggestion of protozoan transport by $M$ cells. Gastroenterology 1986; $90: 583-94$

22 Chen XM, Levine SA, Tietz P, et al. Cryptosporidium parChen XM, Levine SA, Tietz P, et al. Cryptosporidium par-
vum is cytopathic for cultured human biliary epithelia via an apoptotic mechanism. Hepatology 1998;28:906-13. 
23 Hall PA, Coates PJ, Ansari B, et al. Regulation of cell number in the mammalian gastrointestinal tract: the importance of apoptosis. $\mathcal{F}$ Cell Sci 1994;107:3569-77.

24 Kotler DP, Weaver SC, Terzakis JA. Ultrastructural features of epithelial cell degeneration in rectal crypts of patients with AIDS. Am F Surg Pathol 1986;10:531-8.

25 Kotler DP, Gaetz HP, Lange M, et al. Enteropathy associated with the acquired immunodeficiency syndrome. Ann Intern Med 1984;101:421-8.

26 Washington K, Stenzel TT, Buckley R, et al. Gastrointestinal pathology in patients with common variable immunodeficiency and X-linked agammaglobulinemia. Am ₹ Surg Pathol 1996;20:1240-52.

27 Galluci BB, Epstein R, Sale GE, et al. The fine structure of human rectal epithelium in acute graft-versus-host-disease. Am 7 Surg Pathol 1982;6:293-305.

28 Iwamoto M, Koji T, Makiyama K, et al. Apoptosis of crypt epithelial cells in ulcerative colitis. F Pathol 1996;180:152-9.

29 Byers RJ, Marsh P, Parkinson D, et al. Melanosis coli is associated with an increase in colonic epithelial apoptosis associated with an increase in colonic epithelial apoptosis

30 Bloom PD, Boedeker EC. Mucosal immune responses to intestinal bacterial pathogens. Semin Gastrointest Dis 1996; 7:151-66.

31 Lumadue JA, Manabe YC, Moore RD, et al. A clinicopathologic analysis of AIDS-related cryptosporidiosis. AIDS 1998;12:2459-66.

32 Laurent-Crawford AG, Krust B, Muller S, et al. The cytopathic effect of HIV is associated with apoptosis. Virology 1991;185:829-39.

33 Rodgers VD, Fassett R, Kagnoff MF. Abnormalities in intestinal mucosal $\mathrm{T}$ cells in homosexual populations including those with the lymphadenopathy syndrome and acquired immunodeficiency syndrome. Gastroenterology 1986;90:552-8.

34 Ellakany S, Whiteside TL, Schade RR, et al. Analysis of intestinal lymphocyte subpopulations in patients with acquired immunodeficiency syndrome (AIDS) and AIDSacquired immunodeficiency syndrome (AIDS) and

35 Jarry A, Cortez A, René E, et al. Infected cells and immune cells in the gastrointestinal tract of AIDS patients. An immunohistochemical study of 127 cases. Histopathology 19muno 16:133-40.

1990;16:133-40.
Nagata S. Apoptosis by death factor. Cell 1997;88:355-65.

37 Barry M, Heibein JA, Pinkoski MJ, et al. Granzyme B shortcircuits the need for caspase 8 activity during granulemediated cytotoxic T-lymphocyte killing by directly cleaving bid. Mol Cell Biol 2000;20:3781-94

38 Ojcius DM, Perfettini JL, Bonnin A, et al. Caspasedependent apoptosis during infection with Cryptosporidium parvum. Microbes Infect 1999;1:1163-8.

39 Chen W, Harp JA, Harmsen AG, et al. Gamma interferon functions in resistance to Cryptosporidium parvum infection in severe combined immunodeficient mice. Infect Immun 1993;61:3548-51.
40 Chen W, Harp JA, Harmsen AG. Requirements for CD4+ cells and gamma interferon in resolution of established Cryptosporidium parvum infection in mice. Infect Immun 1993;61:3928-32

41 Gomez Morales MA, Ausiello CM, Urbani F, et al. Crude extract and recombinant protein of Cryptosporidium parvum oocysts induce proliferation of human peripheral blood mononuclear cells in vitro. F Infect Dis 1995;172: 211-16.

42 Planchon SM, Martins CA, Guerrant RL, et al. Regulation of intestinal epithelial barrier function by TGF-beta 1. Evidence for its role in abrogating the effect of a $\mathrm{T}$ cell cytokine. F Immunol 1994;153:5730-9.

43 Snijders F, van Deventer SJH, Bartelsman JFW, et al. Diarrhoea in HIV-infected patients: no evidence of cytokinemediated inflammation in jejunal mucosa. AIDS 1995;9: 367-73.

44 Perryman LE, Riggs MW, Mason PH, et al. Kinetics of Cryptosporidium parvum sporozoite neutralization by monoclonal antibodies, immune bovine serum, and immune bovine colostrum. Infect Immun 1990;58:257-9.

45 Bjorneby JM, Riggs MW, Perryman LE. Cryptosporidium parvum merozoites share neutralization-sensitive epitopes with sporozoites. F Immunol 1990;145:298-304.

46 Shield J, Melville C, Novelli V, et al. Bovine colostrum immunoglobulin concentrate for cryptosporidiosis in AIDS. Arch Dis Child 1993;69:451-3.

47 Sweet SP, Rahman D, Challacombe SJ. IgA subclasses in HIV disease: dichotomy between raised levels in serum and decreased secretion rates in saliva. Immunology 1995;86: 556-9.

48 Benhamou Y, Kapel N, Hoang C, et al. Inefficacy of intestinal secretory immune response to Cryptosporidium in acquired immunodeficiency syndrome. Gastroenterology 1995;108:627-35.

49 Walker NI, Harmon BV, Gobe GC, et al. Patterns of cell death. Methods Achiev Exp Pathol 1988;13:18-54.

50 Guarino A, Canani RB, Pozio E, et al. Enterotoxic effect of stool supernatant of Cryptosporidium-infected calves on human jejunum. Gastroenterology 1994;106:28-34.

51 Guarino A, Canani RB, Casola A, et al. Human intestinal cryptosporidiosis: secretory diarrhea and enterotoxic activity in Caco-2 cells. F Infect Dis 1995;171:976-83.

52 Adams RB, Guerrant RL, Zu S, et al. Cryptosporidium parvum infection of intestinal epithelium: morphologic and functional studies in an in vitro model. F Infect Dis 1994;169:170-7.

53 Griffiths JK, Moore R, Dooley S, et al. Cryptosporidium parvum infection of Caco-2 cell monolayers induces an apical monolayer defect, selectively increases transmonolayer permeability, and causes epithelial cell death. Infect Immun 1994;62:4506-14.

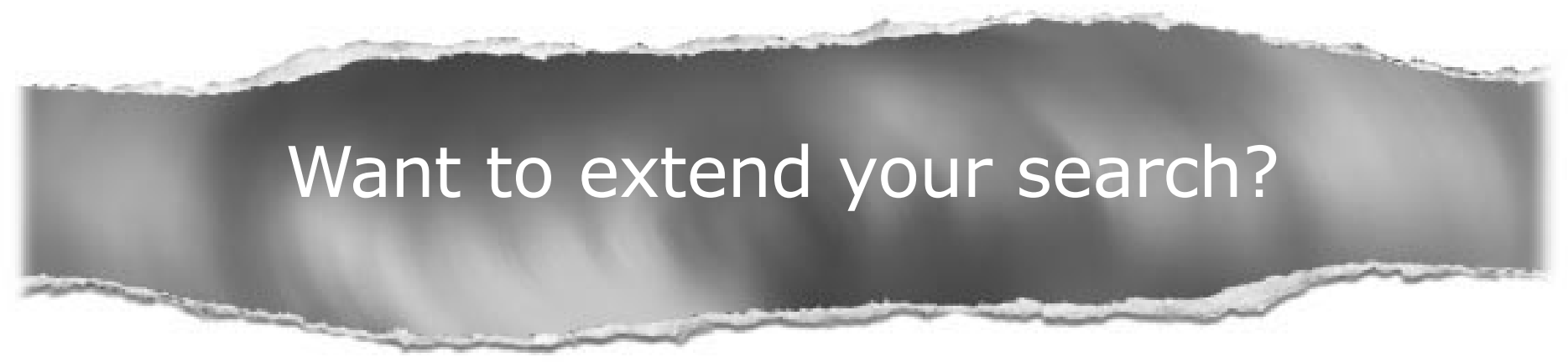

Cross journal searching

If you can't find what you are looking for in the Journal of Clinical Pathology you can extend your search across many of the more than 200 journals available for selection. You can restrict your search to specific subject areas (eg, clinical medicine, basic research), or select specific journals, or search all available titles.

\section{www.jclinpath.com}

